\title{
Predictors of language service availability in U.S. hospitals
}

\author{
Melody K. Schiaffino ${ }^{1, *}$, Mona Al-Amin ${ }^{2}$, Jessica R. Schumacher ${ }^{3}$
}

\begin{abstract}
Background: Hispanics comprise $17 \%$ of the total U.S. population, surpassing African-Americans as the largest minority group. Linguistically, almost 60 million people speak a language other than English. This language diversity can create barriers and additional burden and risk when seeking health services. Patients with Limited English Proficiency (LEP) for example, have been shown to experience a disproportionate risk of poor health outcomes, making the provision of Language Services (LS) in healthcare facilities critical. Research on the determinants of LS adoption has focused more on overall cultural competence and internal managerial decision-making than on measuring LS adoption as a process outcome influenced by contextual or external factors. The current investigation examines the relationship between state policy, service area factors, and hospital characteristics on hospital LS adoption.

Methods: We employ a cross-sectional analysis of survey data from a national sample of hospitals in the American Hospital Association (AHA) database for $2011(\mathrm{~N}=4876)$ to analyze hospital characteristics and outcomes, augmented with additional population data from the American Community Survey (ACS) to estimate language diversity in the hospital service area. Additional data from the National Health Law Program (NHeLP) facilitated the state level Medicaid reimbursement factor.

Results: Only 64\% of hospitals offered LS. Hospitals that adopted LS were more likely to be not-for-profit, in areas with higher than average language diversity, larger, and urban. Hospitals in above average language diverse counties had more than 2 -fold greater odds of adopting LS than less language diverse areas [Adjusted Odds Ratio (AOR): 2.26, $P<0.01]$. Further, hospitals with a strategic orientation toward diversity had nearly 2 -fold greater odds of adopting LS (AOR: 1.90, $P<0.001$ ).

Conclusion: Our findings support the importance of structural and contextual factors as they relate to healthcare delivery. Healthcare organizations must address the needs of the population they serve and align their efforts internally. Current financial incentives do not appear to influence adoption of LS, nor do Medicaid reimbursement funds, thus suggesting that further alignment of incentives. Organizational and system level factors have a place in disparities research and warrant further analysis; additional spatial methods could enhance our understanding of population factors critical to system-level health services research.

Keywords: Limited English Proficiency (LEP), Healthcare Quality, Language Access, Health Disparities, Hospitals Copyright: @ 2014 by Kerman University of Medical Sciences

Citation: Schiaffino MK, Al-Amin M, Schumacher JR. Predictors of language service availability in U.S. hospitals. Int J Health Policy Manag 2014; 3: 259-268. doi: 10.15171/ijhpm.2014.95
\end{abstract}

\section{Article History:}

Received: 20 June 2014

Accepted: 25 September 2014

ePublished: 3 October 2014

\section{Key Messages}

Implications for policy makers

- Hospital leadership plays an important role in the adoption of critical language access for vulnerable populations.

- Language Services (LS) in hospitals are not being provided in an equitable and systematic manner in spite of a federal law and empirical evidence supporting its effectiveness.

- Hospital strategic goals should include an emphasis on diversity.

- Hospitals should consider the demand from their service area in the form of language diversity and other demographic indicators.

- Practical incentives can help policy-makers improve their delivery of LS and lead to better outcomes.

\section{Implications for public}

Growing population diversity and limited English proficient persons may not always have access to Language Services (LS) when they need them. Consumer understanding of rights to LS and education for providers may increase the adoption of hospital LS. These services are a right regardless of ability to pay and can make a difference in the quality of care for patients. 


\section{Introduction}

The United States population continues to grow both in size and diversity. Ethnically, Hispanics-Latinos now comprise $17 \%$ of the total population, surpassing African-Americans as the largest minority group (1). Linguistically, almost 60 million people in the U.S. speak a language other than English (1). This language diversity can create barriers and add an additional burden for those with Limited English Proficiency (LEP) a population that already experiences a disparate risk of poor health outcomes (2).

Language Services (LS) in hospitals facilitate quality access to care by increasing a patient's ability to comply with appointments and procedures resulting in reducing risk of adverse clinical outcomes, such as preventable readmissions, improving patient-provider communication, and increasing patient satisfaction (3-6). In addition to being considered a critical component for the optimization of service quality in hospitals, empirical evidence suggests the absence or poor delivery of LS leads to disparities in health outcomes for LEP patients $(7,8)$. A cross-sectional study of patient adverse event data from six U.S. hospitals showed that a greater proportion of adverse events resulted in physical harm or death for LEP patients as compared to English speaking patients (46.8\% and $24.4 \%$, respectively) (3). LS are also a valuable indicator of cultural competence in healthcare organizations (9).

Despite this federal directive and additional evidence from the Institute of Medicine, inconsistent hospital LS provision persists (10). Executive Order (EO) 13,166 was signed into law by President Clinton in 2000 (11). This EO led to a federal mandate making it law that any organization that received federal funding must provide LS to any person that is in need of it regardless of their ability to pay (12). This law touched off a national response by the research and health community leading to the Culturally and Linguistically Appropriate Services (CLAS) Standards for Healthcare Organizations. Despite the mandate, a 2005 study conducted by The Commonwealth Fund demonstrated that the majority of hospitals did not provide LS at a rate consistent with the linguistic and ethnic diversity of the communities that they serve (13). In the present era of cost-containment and healthcare reform coupled with poor financial performance, hospitals are under significant pressure to prioritize resources. Thus, initiatives to incorporate LS compete with other major change initiatives (e.g. electronic medical records) as hospitals comply with federal mandates. Some hospitals are moving forward with their efforts while others continue to lag behind. The result is that fewer than $20 \%$ of hospitals are consistent in providing adequate LS $(14,15)$. The lack of systematic provision of LS is a critical issue given the evidence that LS are known to influence healthcare quality through several mechanisms, including improved patient safety, and patientphysician communication $(3,5,9)$. The present study aims to measure the prevalence of LS adoption using a national sample of hospitals and assess factors associated with LS adoption.

To date, empirical studies examining LS provision and the factors that influence adoption in hospitals have been limited by methods and scope. Previous research has examined the impact of hospital practices on quality and access without evaluating the characteristics of hospitals that failed to adopt these mandated services, an important gap given the targeting and tailoring of interventions requires this information. For example, federal mandate dictates that all patients have a right to LS, however, the lack of reimbursement for these services may overshadow implementation (16). As of 2014, only California has a comprehensive law related to reimbursement for interpreters (17). Further, reimbursement rates that do exist offer little economic incentive for hospitals to comply (18), given they are only available for Medicaid recipients. A 2006 Joint Commission study found Chief Executive Officers CEOs were motivated to provide "culturally-competent" care, including LS, as a strategic imperative more than for financial ends. Financial incentives, like Medicaid matching funds, were a relatively weak motivator, perhaps due to the state government control over this benefit (18). Moreover, patients seem to be unaware of the federal mandate which may partially contribute to the lack of enthusiasm by hospitals to adopt LS. A 2003 study in California hospitals found 37\% of patients surveyed were unaware that a law existed (15). The way the Medicaid LS reimbursement law is written, even though the option to reimburse is available to all states, it must be activated by each individual state. This has only been done in approximately 13 states to date suggesting a lack of awareness or an insufficient incentive for them to access on reimbursement (16).

Research on the determinants of LS adoption has focused more on overall cultural competence and internal managerial decision-making than on measuring LS adoption as a process outcome influenced by external factors $(18,19)$. In this study we propose a theoretically-driven approach to study LS adoption. Specifically, we will examine the relationship between state policy and service area factors, hospital characteristics, and hospital LS adoption (20,21), using an adaptation of a well-established framework (Donabedian's three-fold perspective on quality healthcare) (22).

Organizational theories provide the scope of hospital structure and process factors that are likely to lead to LS adoption. This is best visualized in Figure 1 in an adapted form of Donabedian's Structure Process Outcome (SPO) model. Structure in this model includes the external or environmental characteristics of an organization while process is related to hospital leadership and strategy decisions that impact affect patient outcomes. We relied on institutional theory to guide the selection of organizational and management factors outlined in the SPO model. According to institutional theory, organizations, in addition to profit, seek legitimacy (23). The notion of legitimacy for a hospital is related to the reputation and the societal "believability" of a hospital's expressed desire to improve the health of its patients (24), contingent on compliance with federal, state, accrediting body policies, regulations, and a commitment to the quality of care it provides to its actual and future patients. According to Meyer and Rowan, institutional theory identifies "norms" that make a hospital a hospital. For example, one would be hard-pressed to find a hospital that does not have a strategic plan or a mission statement; while not mandated they are 


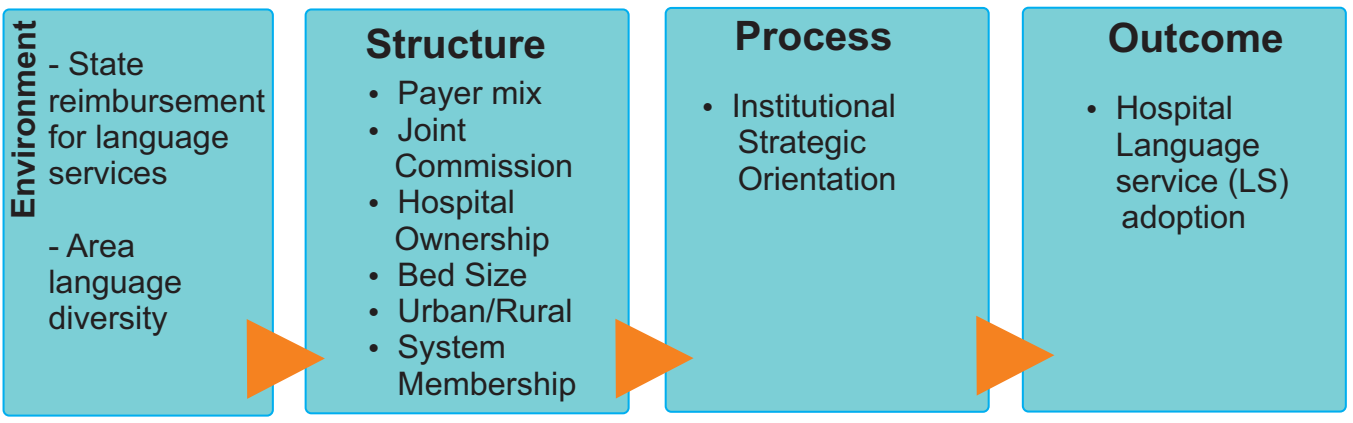

Figure 1. Conceptual framework for hospital LS adoption.

considered standard for legitimacy, much like a doctor wears a white coat (24), the caveat is that they must balance norms with the reality of federal mandates, cost-constraints, and other demands that compete for hospital resources. This search for balance between the hospital and the environment in which it exists is the fundamental sociological motivation of institutional theory (25).

Based on this premise, the presence of a federal language law leads to an assumption that LS provision is systematic and consistent, however, there is mounting evidence this continues to not be the case $(10,14)$. While it remains true that hospitals are driven to adopt innovations or conform to improve legitimacy, the method for reaching this end varies. In the present case, the hospital considers potential gains in "legitimacy" from LS adoption versus associated cost of adoption, while also weighing service area need for LS. DiMaggio and Powell (20) describe this complex process as being characterized by defining the source of transformative pressure, or isomorphism (20): coercive, normative, and mimetic. These pressures exert themselves individually, or in combination, triggering varying degrees of organizational response, from significant changes in hospital mission to no change at all $(26,27)$. Coercive isomorphism is characterized by the level of commitment to state and federal governance that can result in punitive consequences for non-compliance with the law (11). Normative isomorphism reflects the perceived pressure to adapt to the demands of accrediting or professional bodies such as the Joint Commission or to a hospital's own stated norms or strategic plan. This pressure can lead to over- or under-performance depending on need and perceived consequences. Mimetic pressure is external and reflects the competitive benefit hospitals might find from mimicking other hospital's practices and services, which could include a service such as LS (27). Hospitals must balance these competing demands and pressures from their community service area, policy-makers, and other entities. Given this theoretical basis, the following are hypotheses regarding the relation between structural and process factors that relate to hospital LS adoption in the U.S.

H1. Hospitals in counties with greater language diversity will be more likely to adopt LS.

We know that hospitals do not operate in a vacuum (28) and that are influenced by their service area in terms of services, demands, utilization, and costs. Social-demographic factors, like diversity, can compel a hospital to adopt processes or services, in response to normative pressure. National language diversity [defined by the Census as: persons over 5 years old that speak a language other than English at home], is $20.6 \%$, and can range from $2.3 \%$ in West Virginia to $42.2 \%$ in California. This wide variation in language diversity could contribute to the pressure to conform to state social-political pressure, especially among states with greater than average (>21\%) language diversity as they adapt to the access needs of their diverse populations (29). This external pressure could lead hospitals in more language diverse states to respond by adopting LS.

H2. Hospitals with a greater proportion of Medicaid or Medicare patients will be more likely to adopt LS.

H3. LS adoption will differ between states that approved reimbursement for Medicaid-eligible LS and states that did not activate.

In addition to the service area demands attributable to language diversity as described previously, federal and state policies are likely to be an additional source of pressure. Given federal law and the fact that many hospitals receive a large part of their funds from a federal payer (Medicaid and Medicare) most facilities have what Meyer and Rowan termed "interaction", a description of the nature of the relationship between a hospital and a federal payer (21). In the case of hospitals, pressure comes from the quantity of Medicare and Medicaid dollars a hospital receives, calculated as payer mix for the purposes of this analysis. The federal government is one of the largest buyers of health services with approximately $16 \%$ of the U.S.GDP going to healthcare expenditures, thus we can reasonably presume a high level of interaction between hospitals and payers (30). Medicare is especially important since it accounts for a major portion of a hospital's revenue. In hypothesis 2 we argue that the higher the level of dependence on state and federal funds, the more likely a hospital will be to adopt LS (20). Further, the Medicaid program also offers states the option to receive matching funds to reimburse providers for interpreter services provided to Medicaid patients. This is an optional service that must be activated by each state. While very few states have actually activated this mechanism, our theoretical premise supports the additional action of state activation of the optional Medicaid reimbursement for LS as increasing the already significant involvement that comes with payer mix. Thus hypothesis 3 stems from DiMaggio and Powell's seminal publication emphasizing the degree of the interaction between the environment and an organization or hospital (20).

H4. Hospitals with a strategic orientation that includes a focus 
on diversity in their strategic plan are more likely to adopt LS. When examining process factors we begin to see institutional and strategic orientation as a way to examine LS adoption from a system or macro level. DiMaggio and Powell stipulated that organizational pressure to conform is magnified when goals are viewed as ambiguous (20). In the case of the federal policy, the EO was ambiguous in every sense by not explicitly publishing standards for LS provision or emphasize consequences (11). This variation may be part of the reason many hospitals have been remiss in ensuring LS reaches the populations that need them. One manner in which a hospital can succeed is by making the policy a part of the hospital's strategic plan, an institutional norm that is accepted by hospitals as legitimate. The strategic plan, within which strategic orientation can legitimize new policies, will affect professional accreditation, direction, and ultimately, reputation or legitimacy. The inclusion of a focus on diversity in a hospital's strategic plan offers acknowledgement, depth notwithstanding, of a hospital orientation toward health equity, including LEP populations (31).

\section{Methods}

In this analysis, we rely on American Hospital Association (AHA) annual survey database (2011), American Community Survey (ACS) 2009-11 measures, and National Health Law Program (NHeLP) data (2007). The AHA survey is an annual survey that gathers detailed self-reported hospital-level demographic information from hospitals in the United States $(\mathrm{N}=4,876$ in 2011). AHA data was supplemented with the ACS to calculate state language diversity, and NHeLP data to calculate active Medicaid reimbursement policies. Table 1 outlines the operationalization of variables as they relate to the conceptual framework.

The primary outcome variable was hospital provision of language/translation services $(1=$ Services provided by any source; $0=\mathrm{No}$ source for language/translation services selected). The primary predictor variable of interest for Hypothesis 1 was a county-level categorical variable, representing the proportion of the population that spoke a language other than English from the ACS, ranging from less than $2.70 \%$ to greater than $10 \%$.

The primary predictor variable for Hypothesis 2 was payer mix, operationalized as a discrete categorical variable after calculating the payer mix for all hospitals in the sample (national average in 2009 for Medicaid was 18\% and 50\% for Medicare) with $0=$ Lowest quartile and $3=$ The highest. The primary predictor variable for hypothesis 3 was a derived measure of the regulatory and policy environment for language access and whether a given state provides Medicaid LS reimbursement, coded as $1=$ Yes or $0=$ No. State reimbursement for Medicaid-eligible LS are statelevel variables coded as $1=$ Yes and $0=$ States that opted out of this portion of Medicaid. The primary predictor variable for strategic orientation for Hypothesis 4 was described as " $a$ set of goals and objectives that are linked to the organization's Strategic Plan to promote the elimination of disparities and identify strategies to ensure the ethnic and racial composition of the workforce reflects the composition of the community being served". Due to greater than $5 \%$ non-response to this variable, the responses were categorical with $1=$ Yes, $0=$ No, and $2=$ Non-response/Blank.

Other variables associated with the primary predictors and the provision of LS and included in all models included hospital ownership, bed size, U.S. Census region, urban/rural location, system membership, and research hospital status. Not-forprofit hospitals, with religious or altruistic missions, were first established to address the health needs of vulnerable populations (LEP is included in this group) and make up the majority of community hospitals in the country, thus they are more likely to have the greatest geographic proliferation than for-profit hospitals (32). Given their coverage, nonprofit hospitals are more likely to be located in geographic areas that reflect ethnic and linguistic diversity (32). It is also well-documented that larger hospitals and system members are more likely to have the resources and ability to respond to pressure than smaller hospitals. The same applies to research hospitals as they are driven by evidence and count on greater resources to be readily available.

The relation between each predictor variable of interest and LS was initially assessed with a Chi-Square analysis,

Table 1. Operationalization of variables for models.

\begin{tabular}{|c|c|c|c|}
\hline Construct & Variable & Definition & Source \\
\hline Adoption of LS (Outcome) & Hospital adoption of LS & Any LS type selected= Yes & AHA 2011 \\
\hline \multirow[t]{2}{*}{ Environmental Characteristics } & State reimbursement for LS & $\begin{array}{lll}\text { Report indicates } & \text { state approved Medicaid LS } \\
\text { reimbursement } & \mathrm{Y} / \mathrm{N} & \end{array}$ & NHelp 2007 \\
\hline & Area language diversity (county-level) & Categorical low $=0$ and highest $=3$ & ACS 2010-12 \\
\hline \multirow[t]{2}{*}{$\begin{array}{l}\text { Contextual Characteristics } \\
\text { (Structure and Process) }\end{array}$} & Medicare payer mix and Medicaid payer mix & $\begin{array}{l}\text { Each variable is categorical by quartiles } \%, 0 \text { is lowest } \\
\text { percentage; } 3 \text { is highest. }\end{array}$ & AHA 2011 \\
\hline & Diversity in strategic plan & Dichotomous & AHA 2011 \\
\hline \multirow[t]{5}{*}{ Controls } & Hospital ownership & Non-profit, for-profit, government, federal (ref) & AHA 2011 \\
\hline & Bed size & $<50$ beds, $50-100 \ldots 300+$ & \\
\hline & Urban/Rural & Urban, micro, metro, rural & \\
\hline & System membership & Yes, No & \\
\hline & Conducts research & Yes, No & \\
\hline
\end{tabular}

LS= Language Services 
after any correlated variables $(r>0.70)$ were removed from consideration. Multivariable logistic regression analyses assessed the relation between external state factors, hospital characteristics, and LS for each of the hypothesized relationships, controlling for ownership, bed size, urban/rural location, system membership, and research hospital status. A missing variable indicator was added to the diversity measure since the proportion of missing values exceeded 5\%. A Wald Chi-Square Type 3 analysis of effects test indicated good model fit $(P<0.01)$. A separate multivariate logistic regression stratified by state reimbursement was completed to look at changes in the odds ratio with a state-level measure. All analyses were conducted using SAS 9.3 and 9.4 (Cary, N.C.).

\section{Results}

The prevalence of U.S. general hospitals $(\mathrm{N}=4876)$ that offered LS was $64 \%$ in 2011 . Hospitals were more likely to be mid-size, not-for-profit, and located in metropolitan areas (Table 2). Hospitals reporting a diversity emphasis in their strategic plan were more likely to report LS adoption than hospitals without ( $88 \%$ vs. $12 \%)\left(\chi^{2}=1934.90, P<0.01\right)$. Hospitals in states that reimbursed for LS were only slightly more likely to be LS adopters (65\% vs. $64 \%)$, though this difference was not statistically significant $\left(\chi^{2}=3.77, \mathrm{P}=0.43\right)$. LS adoption differed significantly by rates of state language diversity with significance at multiple levels of language diversity $\left(\chi^{2}=123.95, P<0.01\right)$.

$49 \%$ of the smallest hospitals ( $6-24$ beds) to nearly $87 \%$ of the largest hospitals (300+ beds) adopted LS. Hospitals in systems also differed with $69 \%$ adopting LS vs. $31 \%$, though this was higher than those not in systems (58\% LS vs. $43 \%$ no LS).

Results from the multivariable logistic regression models found statistically significant support for Hypotheses 1 and 4 and partial support for Hypotheses 2 and 3. Table 3 provides results from the overall multivariable model, while Table 4 provides results from the stratified analysis for Hypothesis 3. Results indicated significant support for hospital factors and LS adoption but did not support state that had activated Medicaid reimbursement for their Medicaid recipients as a determinant of LS adoption.

For Hypothesis 1, higher levels of state language diversity were associated with greater odds of adopting LS versus the reference group ( $<2.70 \%$ state population language diversity), this association persisted among hospitals in states with language diversity proportions greater than $4.80 \%$ (U.S. average $8.96 \%$ ) with odds of adoption ranging from Adjusted Odds Ratio (AOR) 1.91 to 2.26 greater odds of a hospital adopting LS $(P=0.01$ and $P<0.01$, respectively).

The model reported partial support for $\mathrm{H} 2$ and $\mathrm{H} 4$ (diversity focus in a hospital's strategic plan and a hospital adopting LS). We found 52\% greater odds of LS adoption for hospitals with diversity in their strategic plan as compared to hospitals where it was not included (AOR: $1.90 ; P<0.01$ ), see Table 3. Finally, for Hypothesis 3, though Medicare payer mix was positively related to LS adoption, Medicaid payer mix was not significantly related to LS adoption. Hospitals with a higher than average (U.S. average Medicare payer mix is $49.60 \%$ ) or very high Medicare mix had greater odds of adopting LS.
The AOR for higher than average (51.23\%-62.77\%) payer mix odds were 1.44 (95\% CI: $1.08-1.92 ; P=0.02)$. Very high Medicare payer mix had $48 \%$ greater odds of adopting LS with AOR 1.48 (95\% CI: 1.11-1.98, $P=0.02$ ). Medicaid payer mix levels were all inversely related to adoption of LS, though this result was not statistically significant. State policy for Medicaid reimbursement (H3) and LS adoption was stratified and two separate models were run for states that did and did not reimburse for LS. Hospitals had greater odds of adopting LS as population language diversity increased, though the odds were greater in states that did activate available reimbursement for Medicaid patients versus states that did not take advantage of reimbursement (AOR: 2.38, $P=0.02$ vs. 2.21, $P=0.01$ ) detailed results are visible in Table 4 .

When looking at controlling factors, not-for-profit hospitals had nearly 7-fold greater odds of providing LS with an AOR of 6.96 (95\% CI: 3.91-12.37) when compared to the reference group (federal hospitals), for-profit hospitals were nearly 4-fold greater as well (AOR: 3.65; 95\% CI: 2.11-6.29). Odds of adopting LS were nearly 4 -fold greater among the largest hospitals (greater than 300 beds; $P<0.01$ ), this association decreased as hospital size decreased. Only hospitals in metropolitan areas (defined as have $>50,000$ people) had significantly greater odds of adopting LS when compared to rural hospitals $(\mathrm{AOR}=2.11 ; P=0.001)$. However, geographic differences indicated 2-fold or greater adjusted odds of adopting LS, this association was significant $(P<0.01-0.04)$. These results were not included in the tables.

\section{Discussion}

The analyses in the current analysis were guided by institutional theory and assessed the relationship between contextual (structure) and organizational (process) factors that contribute to hospital LS adoption. The results of our study update and expand on findings from national studies that have found significant variation in the adoption of LS in hospitals across the U.S. (14,33). Our findings lend further support to institutional theory and indicate that hospital adoption of policies such as the provision of LS, is complex and influenced by factors external to the organization.

Perhaps the most interesting organizational-level predictor is a hospital's focus on diversity in their strategic plans (H4) which suggests a need for top management to be committed to diversity as part of its strategic goals and consequently, long-term planning. Ultimately, these positions help a hospital achieve diversity aims and suggest adoption of LS as a strategic goal may be more effective in triggering isomorphism than current external pressures or policies. Accrediting organizations such as the Joint Commission could recognize this attribute and encourage adoption of this behavior to create "normative" momentum. The Joint Commission emphasis on patient safety has now made LS a required service for accreditation, not to mention the patient safety imperative that they emphasize. Our findings indicate hospitals in counties with higher language diversity in their service area are significantly more likely to adopt LS. Language diversity (H1). This finding is particularly important from a policy perspective as it indicates that 
Table 2. Contextual and organizational characteristics of general hospitals responding to the AHA 2011 survey by language service provision status*.

\begin{tabular}{llll}
\hline $\boldsymbol{P}$ & Total & Adopted LS & Non-Adopter of LS \\
\hline
\end{tabular}

\section{Hypotheses}

State where hospital is located reimburses for LS for Medicaid

$\begin{array}{llll}\text { Yes } & 1304 & 65 & 35 \\ \text { No } & 3572 & 64 & 36\end{array}$

Hospital service area language diversity ${ }^{\mathrm{a}}$

\begin{tabular}{|c|c|c|c|c|}
\hline$<2.70 \%$ & 650 & 46 & 54 & \\
\hline $2.80 \%-4.80 \%$ & 906 & 60 & 40 & \\
\hline 4.90\%-10\% [U.S. avg. 8.96\%] & 1157 & 69 & 31 & \\
\hline$>10 \%$ & 2109 & 71 & 29 & $<0.01$ \\
\hline$<25 \%$ & 149 & 14 & 86 & \\
\hline $26 \%-50 \%$ & 821 & 41 & 59 & \\
\hline $51 \%-75 \%$ & 3044 & 63 & 37 & \\
\hline$>50 \%$ & 877 & 81 & 19 & $<0.01$ \\
\hline
\end{tabular}

\section{Hospital}

Medicaid payer mix (U.S. Mean $=18.09 \%)^{\mathrm{b}}$

$\begin{array}{llll}<8.31 \% & 1218 & 60 & 49 \\ 8.32 \%-14.98 \% & 1220 & 68 & 32 \\ 14.99 \%-22.28 \% \text { [U.S. avg. 18.09\%] } & 1219 & 59 & 41 \\ >22.29 \% & 1219 & 69 & 31\end{array}$

Medicare payer mix (U.S. Mean $=49.60 \%)^{\mathrm{b}}$

$<40.81 \%$

40.82\%-51.22\% [U.S. avg. 49.60]

$51.23 \%-62.77 \%$

$>62.78 \%$

Hospital diversity strategy

Yes

No

No response

Bed size

6-49 Beds

50-99

100-199

200-299

$300+$ Beds

Hospital ownership type

Not-for-profit

For-profit/private

Local government, non-federal

Federal gov. (DOD, Navy)

U.S. census region ${ }^{c}$

New England
Mid Atlantic
South Atlantic
East North Central
East South Central

1219

1155

1283

1219

2381

1096

1399

1584

852

1025

590

825

$\begin{array}{lll}2776 & 74 & 26 \\ 841 & 50 & 50 \\ 1066 & 56 & 44 \\ 193 & 28 & 72\end{array}$

174

83

17

409

74

726

67

729

417

$\begin{array}{ll}64 & 36 \\ 59 & 41 \\ 68 & 32 \\ 65 & 35\end{array}$

$88 \quad 12$

$67 \quad 33$

22

78
49

32

41

31

$<0.01$

$<0.01$

$<0.01$

$<0.01$

$<0.01$ 


\section{Table 2 . Continued}

\begin{tabular}{|c|c|c|c|c|}
\hline West North Central & 688 & 61 & 39 & \\
\hline West South Central & 716 & 64 & 36 & \\
\hline Mountain & 403 & 56 & 44 & \\
\hline Pacific and assoc. areas (PR, Guam, etc) & 547 & 58 & 42 & $<0.01$ \\
\hline \multicolumn{5}{|l|}{ Urban/Rural designation of hospital } \\
\hline Division & 688 & 75 & 25 & \\
\hline Metro & 2127 & 71 & 29 & \\
\hline Micro & 868 & 64 & 36 & \\
\hline Rural & 1193 & 45 & 55 & $<0.01$ \\
\hline \multicolumn{5}{|l|}{ Joint commission membership } \\
\hline Yes & 3240 & 72 & 28 & \\
\hline No & 1636 & 49 & 51 & $<0.01$ \\
\hline \multicolumn{5}{|l|}{ Hospital system membership } \\
\hline Yes & 2860 & 68.9 & 31 & \\
\hline No & 2016 & 57.5 & 43 & $<0.01$ \\
\hline
\end{tabular}

$\mathrm{AHA}=$ American Hospital Association; LS= Language Services.

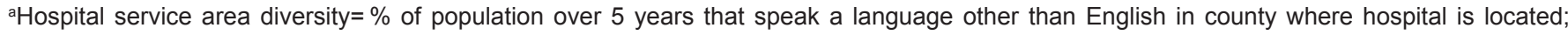
${ }^{\mathrm{b}}$ Medicaid and Medicare payer mix calculated using formula: Medicaid or Medicare Discharges $\div$ Total Hospital Admissions; ${ }^{\circ}$ East South Central (Reference Group)= KY, TN, AL, MS; New England= ME, NH, MA, RI, CN, VT; Mid Atlantic= NY, NJ, PA; South Atlantic= DE, MD, DC, VA, WV, NC, SC, GA, FL; East North Central= OH, IN, IL, MI, WI; West North Central= MN, IA, MO, ND, SD, NE, KS; West South Central= AR, LA, OK, TX; Mountain= MT, ID, WY, CO, NM, AZ, UT, NV; Pacific and Assoc. Areas=WA, OR, CA, AK, HI, Marshall Islands, PR, VI, Guam, Am.Samoa, N.Marianas $(n=4876)$.

${ }^{*} \mathrm{~N}=4891$ (Chi-Square reporting Row \%).

Table 3. AOR of LS adoption by hypothesis

\begin{tabular}{|c|c|c|c|c|c|}
\hline & \multicolumn{5}{|c|}{ Hospital adoption of LS } \\
\hline & Crude OR & $95 \% \mathrm{Cl}$ & AOR & $95 \% \mathrm{Cl}$ & $P$ \\
\hline \multicolumn{6}{|l|}{ Language diversity } \\
\hline$<2.70 \%$ & Ref & Ref & Ref & - & - \\
\hline $2.80-4.80 \%$ & 1.76 & $1.43-2.16$ & 1.39 & $1.06-1.81$ & 0.13 \\
\hline $4.80 \%-10 \%$ [U.S. avg. $8.96 \%$ ] & 2.59 & $2.12-3.15$ & 1.91 & $1.46-2.51$ & 0.01 \\
\hline$>10 \%$ & 2.84 & $2.37-3.40$ & 2.26 & $1.69-3.03$ & $<0.01$ \\
\hline \multicolumn{6}{|l|}{ Medicaid payer mix } \\
\hline$<8.31 \%$ & Ref & Ref & Ref & - & - \\
\hline $8.32 \%-14.98 \%$ & 1.41 & $1.20-1.67$ & 0.92 & $0.72-1.19$ & 0.22 \\
\hline $14.99 \%-22.28 \%$ [U.S. avg. $18.09 \%$ ] & 1.00 & $0.85-1.17$ & 0.61 & $0.46-0.81$ & 0.01 \\
\hline$>22.29 \%$ & 1.34 & $1.30-1.85$ & 0.86 & $0.63-1.17$ & 0.75 \\
\hline \multicolumn{6}{|l|}{ Medicare payer mix } \\
\hline$<40.81 \%$ & Ref & Ref & Ref & - & - \\
\hline $40.82 \%-51.22 \%$ [U.S. avg. $49.60 \%$ ] & 0.82 & $0.69-0.97$ & 0.99 & $0.75-1.31$ & 0.02 \\
\hline $51.23 \%-62.77 \%$ & 1.22 & $1.03-1.45$ & 1.44 & $1.08-1.92$ & 0.02 \\
\hline$>62.78 \%$ & 1.04 & $0.88-1.23$ & 1.48 & $1.11-1.98$ & 0.06 \\
\hline \multicolumn{6}{|l|}{ Strategic orientation } \\
\hline Yes & 3.53 & $2.96-4.22$ & 1.90 & $1.55-2.33$ & $<0.01$ \\
\hline No & Ref & Ref & Ref & - & - \\
\hline No response & 0.14 & $0.11-0.16$ & 0.08 & $0.06-0.10$ & $<0.01$ \\
\hline
\end{tabular}

AOR= Adjusted Odds Ratio; LS= Language Services; $C l=$ Confidence Interval.

hospitals may respond to population needs more strongly than federal mandates that lack clear objectives, strong financial incentives or even penalties. Further contextual study on competition may also look at the proportion of hospital adopting LS. Organizations seek to imitate the practices of their competitors in order to enhance their legitimacy. These efforts and initiatives should be recognized by policy-makers and public health stakeholders at the state and national levels in order to encourage other hospitals to follow suit. Competitive factors including market penetration of managed care are also factors related to a hospital's resources, from the perspective of institutional theory, hospitals in areas with many hospitals that offer LS may also provide a mimetic competitive pressure to provide LS (27). The lack of significance between Medicaid payer mix and LS and the positive relationship between Medicare payer mix and LS adoption raise interesting 
Table 4. Stratified multivariate model comparing hospitals in a state that does and does not reimburse for LS for Medicaid recipients.

\begin{tabular}{|c|c|c|c|c|c|c|}
\hline & \multicolumn{6}{|c|}{ Hospitals location in state with and without policy } \\
\hline & \multicolumn{2}{|c|}{$\begin{array}{l}\text { State reimbursement } \\
\text { for LS }\end{array}$} & \multirow{2}{*}{$\begin{array}{c}N=1,304 \\
\text { LS Yes: } 837(64.20 \%) \\
P\end{array}$} & \multicolumn{2}{|c|}{ No state reimbursement for LS } & \multirow{2}{*}{$\begin{array}{c}N=3,572 \\
\text { LS Yes: } 2,273(63.40 \%) \\
P\end{array}$} \\
\hline & AOR & $95 \% \mathrm{Cl}$ & & AOR & $95 \% \mathrm{Cl}$ & \\
\hline \multicolumn{7}{|l|}{ Language diversity } \\
\hline$<2.70 \%$ & Ref & - & - & Ref & - & - \\
\hline $2.80-4.80 \%$ & 1.33 & $0.81-2.18$ & 0.22 & 1.39 & $1.01-1.91$ & 0.25 \\
\hline $4.80-10 \%$ [U.S. avg. 8.96\%] & 2.06 & $1.22-3.49$ & 0.08 & 1.86 & $1.35-2.58$ & 0.04 \\
\hline$>10 \%$ & 2.38 & $1.31-4.31$ & 0.02 & 2.21 & $1.56-3.14$ & $<0.01$ \\
\hline \multicolumn{7}{|l|}{ Medicaid payer mix } \\
\hline$<8.31 \%$ & Ref & - & - & Ref & - & - \\
\hline $8.32 \%-14.98 \%$ & 0.83 & $0.49-1.41$ & 0.52 & 0.93 & $0.70-1.25$ & 0.13 \\
\hline $14.99 \%-22.28 \%$ [US avg. $18.09 \%]$ & 0.81 & $0.46-1.44$ & 0.42 & 0.57 & $0.41-0.79$ & $<0.01$ \\
\hline$>22.29$ & 1.08 & $0.59-2.00$ & 0.39 & 0.81 & $0.56-1.17$ & 0.97 \\
\hline \multicolumn{7}{|l|}{ Medicare payer mix } \\
\hline$<40.81 \%$ & Ref & - & - & Ref & - & - \\
\hline 40.82\%-51.22 [U.S. avg. 49.60] & 0.92 & $0.55-1.54$ & 0.10 & 0.98 & $0.70-1.36$ & 0.04 \\
\hline $51.23 \%-62.77 \%$ & 1.34 & $0.74-2.42$ & 0.54 & 1.46 & $1.05-2.04$ & 0.03 \\
\hline$>62.78$ & 1.71 & $0.95-3.08$ & 0.05 & 1.45 & $1.03-2.04$ & 0.06 \\
\hline \multicolumn{7}{|l|}{ Strategic orientation } \\
\hline Yes & 2.21 & $1.48-3.30$ & $<0.01$ & 1.82 & $1.43-2.31$ & $<0.01$ \\
\hline No & Ref & - & - & Ref & - & - \\
\hline No response & 0.11 & $0.07-0.18$ & $<0.01$ & 0.07 & $0.05-0.10$ & $<0.01$ \\
\hline
\end{tabular}

AOR= Adjusted Odds Ratio; LS= Language Services; Cl= Confidence Interval.

questions given that reimbursement for LS is only available to Medicaid patients, not Medicare. Hospitals might not view the penalties or incentives for providing LS as strong enough to justify the cost of adopting and implementing LS. The lack of association also suggests that while a federal mandate exists and provides an, albeit small, economic incentive this does not appear to be sufficient in motivating hospitals to adopt LS. Institutional theory suggests that mandates have to be directly linked with incentives for better hospital compliance and adherence; these mechanisms include reimbursement or other alternative means.

These findings and growing empirical evidence also support the importance of LS provision not just from a societal perspective where LS provision is critical to the quality of care provided to LEP and vulnerable patients, and a public health and policy imperative, but also potentially a business perspective, whereby it enhances the marketability and consequently market share of healthcare organizations serving these populations (34). Future regulations and payment mechanisms should consider the benefits of reflecting cultural competence and non-efficiency benchmarks as a component. Additional research in looking at the spatial differences in the provision and process factors associated with LS would also complement existing literature that indicates quality and outcomes can vary spatially $(35,36)$.

\section{Limitations}

The present analysis does contain limitations common for self-reported, cross-sectional survey data. Only one year of data was available for analysis. However, the federal mandate would have been nearly a decade old at the time of the data and should have been well in place by the time of the analysis.
The contextual measure of language diversity and states with policies that allow reimbursement for LS among Medicaid recipients may be a larger than desired unit of analysis since every hospital in one state is not necessarily like the others in the same state. However, since all hospitals in the state are bound by state policy environment and policies, such as state certificate of need, reimbursement for LS, and operating regulations among others, variables were matched to the state level of analysis for contextual comparison while controlling for urban, region, and bed size in the model. The model was stratified for this purpose. We must also note that the present analysis only examines one facet of the multi-dimensional construct that is cultural competence. While LS are a necessary component of what makes a hospital compliant with the federal mandate, they are not automatically sufficient to ensure culturally appropriate services for patients. Thus the proficiency and availability of LS, which includes all aspects of the LS delivery continuum, including quality and mode of LS, training of hospital staff to activate LS, and hospital policies must be further explored as a quality and patient safety imperative.

\section{Conclusion}

Our analysis yielded a number of findings with considerable policy implications; strategic orientation appears to play a significant role in hospitals that report LS adoption warranting a better understanding of hospital decisions at the institutional or system level. The significance of these nonefficiency measures may be to the benefit of the populations that hospitals serve and an opportunity for incentives and growth. Hospitals with diversity as a strategic imperative are also a benefit to their community as they embrace the 
demands of growing diversity in the U.S. Response continues to mount for this important service and will continue to do so in this new era of the Affordable Care Act (ACA) $(37,38)$. Research dedicated to making the market case for healthcare organizations to adopt LS as a strategic imperative would undoubtedly fold executive visionaries into the same call to action that healthcare and social justice advocates have been pushing forward for decades: LS (and ultimately culturallycompetent healthcare) benefits patients, they benefit hospitals, they avoid costly medical errors, and they facilitate critical patient-provider communication $(39,40)$. Additional research in understanding the level of provision of LS would also help in understanding not only factors that are associated with adoption but also factors associated with provision that is culturally competent and of true benefit to recipients. Future research may also focus on policies that encourage hospitals to better consider the resource implications of offering LS as opposed to punitive policies tied to efficiency and profit that are not regulated or enforced until there is a much greater human and financial cost involved.

\section{Ethical issues}

Not applicable.

\section{Competing interests}

The authors declare that they have no competing interests.

\section{Authors' contributions}

MKS and MA developed theoretical premise and conceptual model, JRS and MKS applied methods section, MKS compiled and analyzed all data and results. All authors revised and edited.

\section{Authors' affiliations}

${ }^{1}$ San Diego State University, San Diego, CA, USA. 2Suffolk University, Boston, MA, USA. ${ }^{3}$ University of Wisconsin-Madison, Madison, WI, USA.

\section{References}

1. Shin H, Kominski R. Language Use in the United States: 2007. Washington, DC: U.S. Census Bureau; 2010.

2. Pandya C, Batalova J, McHugh M. Limited English Proficient Individuals in the United States: Number, Share, Growth, and Linguistic Diversity. Washington, DC: Migration Policy Institute; 2011.

3. Divi C, Koss RG, Schmaltz SP, Loeb JM. Language proficiency and adverse events in US hospitals: a pilot study. Int J Qual Health Care 2007; 19: 60-7. doi: 10.1093/intqhc/mzl069

4. Karliner LS, Jacobs EA, Chen AH, Mutha S. Do professional interpreters improve clinical care for patients with limited English proficiency? A systematic review of the literature. Health Serv Res 2007; 42: 727-54. doi: 10.1111/j.1475-6773.2006.00629.x

5. Anderson LM, Scrimshaw SC, Fullilove MT, Fielding JE, Normand J. Culturally competent healthcare systems. A systematic review. Am J Prev Med 2003; 24: 68-79.

6. Lindholm M, Hargraves JL, Ferguson WJ, Reed G. Professional language interpretation and inpatient length of stay and readmission rates. J Gen Intern Med 2012; 27: 1294-9. doi: 10.1007/s11606-012-2041-5

7. Cheng EM, Chen A, Cunningham W. Primary language and receipt of recommended health care among Hispanics in the United States. J Gen Intern Med 2007; 22: 283-8. doi: 10.1007/ s11606-007-0346-6

8. $\mathrm{Ku} \mathrm{L}$, Flores G. Pay now or pay later: providing interpreter services in health care. Health Aff (Millwood) 2005; 24: 435-44. doi: $10.1377 /$ hlthaff.24.2.435

9. Goode TD, Dunne MC, Bronheim SM. The Evidence Base for Cultural and Linguistic Competency in Health Care. Georgetown University: National Center for Cultural Competence, Center for Child and Human Development; 2006. Report No. 962.

10. Wilson-Stronks A, Lee K, Cordero C, Kopp A, Galvez E. One Size does not Fit All: Meeting the Healthcare Needs of Diverse Populations. Oakbrook, IL: The Joint Commission; 2008.

11. Federal Register. Executive Order 13166 - Improving Access to Services for Persons with Limited English Proficiency. Washington, DC: Federal Register; 2000. p. 6.

12. Federal Register. Guidance to Federal Financial Assistance Recipients Regarding Title VI Prohibition Against National Origin Discrimination Affecting Limited English Proficient Persons. Washington, DC: Coordination and Review Section, Civil Rights Division; 2002.

13. Diamond LC, Luft HS, Chung S, Jacobs EA. "Does This Doctor Speak My Language?" Improving the Characterization of Physician Non-English Language Skills. Health Serv Res 2011. doi: 10.1111/j.1475-6773.2011.01338.x

14. Diamond LC, Wilson-Stronks A, Jacobs EA. Do hospitals measure up to the national culturally and linguistically appropriate services standards? Med Care 2010; 48: 1080-7. doi: 10.1097/ MLR.0b013e3181f380bc

15. Grubbs V, Chen $A H$, Bindman AB, Vittinghoff $E$, Fernandez $A$. Effect of awareness of language law on language access in the health care setting. J Gen Intern Med 2006; 21: 683-8. doi: 10.1111/j.1525-1497.2006.00492.x

16. Ortega A. . . . And health care for all: immigrants in the shadow of the promise of universal health care. Am J Law Med 2009; 35: 185-204.

17. Youdelman MK. The medical tongue: U.S. laws and policies on language access. Health Aff (Millwood) 2008; 27: 424-33. doi: 10.1377/hlthaff.27.2.424

18. Wilson-Stronks A, Mutha S. From the perspective of CEOs: what motivates hospitals to embrace cultural competence? J Health Manag 2010; 55: 339-51.

19. Guerrero EG. Managerial capacity and adoption of culturally competent practices in outpatient substance abuse treatment organizations. Journal of Substance Abuse Treatment 2010; 39: 329-39. doi: 10.1016/j.jsat.2010.07.004

20. DiMaggio P, Powell W. The Iron Cage Revisited: Institutional Isomorphism and collective rationality in organizational fields. American Sociologica Review 1983; 48: 147-60.

21. Meyer J, Rowan B. Institutionalized Organizations: Formal Structure as Myth and Ceremony. American Journal of Sociology 1977; 83: 340-63.

22. Donabedian A. The quality of care. JAMA 1988; 260: 1743-8.

23. DiMaggio PJ, Powell WW. The Iron Cage Revisited: Institutional Isomorphism and Collective Rationality in Organizational Fields. American Sociological Review 1983; 48: 13.

24. Suchman MC. Managing Legitimacy - Strategic and Institutional Approaches. Academy of Management Review 1995; 20: 571 610. doi: $10.2307 / 258788$

25. Powell WW, DiMaggio P. The New institutionalism in organizational analysis. Chicago: University of Chicago Press; 1991.

26. Chen JT, Coull BA, Waterman PD, Schwartz J, Krieger N. Methodologic implications of social inequalities for analyzing health disparities in large spatiotemporal data sets: an example using breast cancer incidence data (Northern and Southern California, 1988--2002). Stat Med 2008; 27: 3957-83. doi: $10.1002 / \operatorname{sim} .3263$

27. Scott WR, Davis GF. Organizations and organizing : rational, 
natural, and open system perspectives. 1st ed. Upper Saddle River, NJ: Pearson Prentice Hall; 2007.

28. Luft HR, Garnick D, Maerki S, McPhee S. The Role of Specialized Clinical Services in Competition among Hospitals. Inquiry 1986; 23: 11.

29. Greenwood R. The SAGE handbook of organizational institutionalism. Los Angeles, London: SAGE; 2008.

30. Pearson M. Disparities in health expenditures across OECD countries: Why does the United States spend so much more than other countries?. 2009. Available from: http://www.oecd. org/unitedstates/43800977.pdf

31. Chen AH, Youdelman MK, Brooks J. The legal framework for language access in healthcare settings: Title $\mathrm{VI}$ and beyond. J Gen Intern Med 2007; 22: 362-7. doi: 10.1007/s11606-0070366-2

32. Norton EC, Staiger DO. How hospital ownership affects access to care for the uninsured. The Rand Journal of Economics 1994; 25: 171-85.

33. Wilson-Stronks A, Galvez E. Hospitals, Language and Culture: A Snapshot of the Nation: Exploring Cultural and Linguistic Services in the Nation's Hospitals. Joint Commission; 2007.

34. Weech-Maldonado R, Al-Amin M, Nishimi RY, Salam F. Enhancing the cultural competency of health-care organizations. Adv Health Care Manag 2011; 10: 43-67.
35. Weech-Maldonado R, Fongwa MN, Gutierrez P, Hays RD. Language and regional differences in evaluations of Medicare managed care by Hispanics. Health Serv Res 2008; 43: 552-68. doi: 10.1111/j.1475-6773.2007.00796.x

36. Wennberg DE. Variation in the delivery of health care: The stakes are high. Annals of Internal Medicine 1998; 128: 866-8.

37. Betancourt JR, Tan-McGrory A. Creating a safe, high-quality healthcare system for all: meeting the needs of limited English proficient populations; Comment on "Patient safety and healthcare quality: the case for language access". Int $J$ Health Policy Manag 2014; 2: 91-4. doi: 10.15171/ijhpm.2014.21

38. Andrulis DP, Jahnke LR, Siddiqui NJ, Cooper MR. Implementing Cultural and Linguistic Requirements in Health Insurance Exchanges. Texas Health Institute; 2013. Available from: http:// www.texashealthinstitute.org/health-care-reform.html

39. Alliance of Community Health Plans Foundation. Making the Business Case for Culturally and Linguistically Appropriate Services in Health Care: Case Studies from the Field. Merck Foundation; 2007.

40. Weech-Maldonado R, Elliott MN, Pradhan R, Schiller C, Dreachslin J, Hays RD. Moving towards culturally competent health systems: organizational and market factors. Soc Sci Med 2012; 75: 815-22. doi: 10.1016/j.socscimed.2012.03.053 